\title{
PRÁTICAS DE LEITURAS ESCOLARES NOS ANOS 20: Os usos do Almanaque Biotônico Fontoura
}

\author{
Marcelo Oliano Machado ${ }^{1}$ \\ Oliano@hotmail.com \\ Ednéia Regina Rossi ${ }^{2}$ \\ errossi@uem.br \\ Elaine Rodrigues ${ }^{3}$
}

Universidade Estadual de Maringá - UEM

\section{RESUMO}

Neste artigo, por meio da memória de seus leitores, buscamos identificar o Almanaque Biotônico Fontoura como fonte para análise da história das práticas de leituras escolares nas primeiras décadas do século XX. Partimos do entendimento de que o Almanaque não foi apenas um livreto de divulgação medicamentosa. Distribuído, a princípio, apenas em farmácias, ele adentrou os muros das escolas, transformando-se em material de leitura de muitos jovens e crianças. Transformado em material de leitura, ele circulou nos ambientes escolares, como material de apoio didático.

Palavras-chave: Almanaque do Biotônico Fontoura; História da Educação; Práticas de leituras; Brasil (1920).

\section{READING PRACTICES IN THE SCHOOL IN THE 1920s: THE USE OF THE ALMANAQUE BIOTÔNICO FONTOURA}

\begin{abstract}
Working on readers' memories, current analysis identifies the Almanaque Biotônico Fontoura as a source for the analysis of school reading practices during the first decades of the $20^{\text {th }}$ century. In fact, the Almanaque was not merely a booklet for the advertisement of drugs. Although it was formerly distributed in pharmacies, the booklet reached the school and was transformed into reading material by many young people and children. As reading material, the Almanaque spread in schools as a didactic support material.
\end{abstract}

Keywords: Almanaque do Biotônico Fontoura; History of Education; reading practices; 1920 Brazil.

Por meio da memória de leitores do Almanaque Fontoura, a intenção foi identificar os usos feitos do Almanaque, que teve sua primeira tiragem em 1920. Com linguagem simples e associada diretamente às ilustrações dos textos, este material de 
leitura podia ser compreendido tanto por aqueles que estavam em processo de alfabetização quanto também pelos analfabetos. Afinal, em um país cujo número de analfabetos equivalia a 64,9\% da população (dados IBGE-1920), atrelar o texto à imagem e vice versa pode ter sido um recurso dos idealizadores do Almanaque (Monteiro Lobato e Candido Fontoura) para tornar a história do Jeca Tatuzinho compreendida pelo maior número possível de habitantes.

Neste texto, procuramos identificar as particularidades do almanaque como material de leitura fecundo para análise da história das práticas de leituras escolares nas primeira décadas do século XX. Partimos do entendimento de que o Almanaque não foi apenas um livreto de divulgação medicamentosa. Transformado em material de leitura, ele inauguraria, juntamente com outras iniciativas, um campo de estratégias criadas com o objetivo de alterar ou criar novos hábitos e costumes em seus leitores.

Os depoimentos utilizados como fonte foram localizados em outros trabalhos de pesquisa ou em livros de memória, cujos objetivos se distanciam daqueles definidos para este trabalho. Iniciemos com o depoimento de uma de suas utilizadoras:

[[...]] A primeira vez que vi um armanaque foi no orfanato. Acho que era 1928. Eles mostrava prás criança, prá num andá discarça. O que era de mais interesse era a história do Jeca Tatu. A professora aproveitava $[\ldots]$

Lá se usava os remédio indicado nele. No orfanato tinha o livro Sagrado e o armanaque. A professora ensinava a chave. Eu quero dizê, as letra. Elas acaba sendo a chave, sem elas ocê num entra. Num lê. Aí eu procurava as letra no armanaque.

Quando eu cresci, fui trabalhá em São Paulo, na casa da Familia Mello. [...]. Lá tamém tinha o armanaque. Como ele tinha muito desenho eu usava prás criança estudá, copiando as palavra e olhando nos desenho. Fazia lição com Jeca Tatu. Prá ensiná as palavra do armanaque[...]. Aí eu casei e fui pro sítio prantá. [...] E o jeito era o armanaque. O único lugar prá saber quando e o que prantá. Nem é só isso. E nome pros filho? Tirado do Livro Sagrado e dos armanaque. As criança andava tudo carçada. Aprendi lá. Prá não dá bicho[...] Tudo a gente olhava nele. Eles davam na Farmácia. [...] Todos na casa interessava. Aqueles que conseguia lê um poco, lia pros outro. Assim né, de ouví e vê, acabava sabendo e lia (PARK, 1999, p. 147-148).

A depoente deixa ver a importância que os almanaques em geral e, em particular, o Almanaque Fontoura assumiram na vida dos sujeitos. Como guia de práticas higiênicas, como material para alfabetização e estudo, como orientação para o trabalho na roça ou, ainda, como inspirador de nomes para os filhos, os usos feitos desse Almanaque foram diversificados. Ele circulou não apenas no ambiente rural, mas em grandes centros e também em cidades do interior. Um livreto que, no mote de sua criação, para o editor, não passava de um almanaque como outro qualquer, para se tornar, após a primeira edição, um fenômeno de distribuição e de consumo. 
Perceba o leitor que a união de elementos relacionados à saúde, educação e literatura, atrelados à publicidade, propiciou ao Almanaque do Biotônico Fontoura não apenas a característica de um livreto que alertava os brasileiros, especialmente aqueles que viviam no campo, a respeito dos sintomas e ciclos da ancilostomose (popularmente conhecida como Amarelão). O almanaque também indicava medidas sanitárias de prevenção dessa doença e, consequentemente, divulgava o Biotônico Fontoura como o melhor remédio para tal mazela.

Um dia um doutor portou lá por causa da chuva e espantou-se de tanta miséria. Vendo o caboclo tão amarelo e magro, resolveu examiná-lo. Amigo Jeca, o que você tem é doença. - Pode ser. Sinto uma canseira sem fim, e dor de cabeça, e uma pontada aqui no peito, que responde na cacunda. - Isso mesmo. Você sofre de ancilostomíase. - Anci[...] o que? - Sofre de amarelão, entende? Uma doença que muitos confundem com a maleita. - Essa tal maleita não é sezão? - Isso mesmo. Maleita, sezão, febre palustre ou febre intermitente: tudo a mesma coisa. A sezão também produz anemia, moleza e esse desânimo do amarelão; mas é diferente. Conhece-se a maleita pelo arrepio ou calafrio que dá, pois é uma febre que vem sempre em horas certas e com muito suor. Quem sofre de sezão sara com o MALEITOSAN FONTOURA. Quem sofre de amarelão sara com a ANKILOSTOMINA FONTOURA. Eu vou curar você (LOBATO, 1950, p. 3).

Foi a partir dessa recriação fictícia que Lobato e Fontoura iniciaram a participação na campanha sanitarista que assolou o Brasil da década de 1920. É também através desse mesmo Almanaque, que Lobato reestrutura a imagem de sertanejo por ele representada no artigo "Velha Praga", de 1914, como um "parasita, um piolho da terra [[...]] seminômade, inadaptável à civilização, mas que vive à beira dela, na penumbra das zonas fronteiriça" (LOBATO, 1982, p. 235-236). No contexto das campanhas sanitaristas, Lobato insere o sertanejo em um contexto que tem mais dimensões positivas que as outrora descritas na sua primeira aparição, em 1914. O Jeca torna-se uma espécie de vítima das mazelas sociais, entre elas, a falta de políticas de saneamento, afinal, como definiu o próprio autor: "O Jeca não é assim, esta assim. A saúde pública brasileira vai mal e a apatia do caipira é decorrente de suas enfermidades" (LOBATO, 1982, p. 234). Essa dualidade representativa da personagem pode estar intrinsecamente associada às mudanças ocorridas no país nas primeiras décadas do século XX.

Por um lado, se cidades como Rio de Janeiro e São Paulo incitavam, no início do século XX, perspectivas de desenvolvimento baseadas na hegemonia cultural das fábricas. Isto é, o operário precisava estar preparado para atuar em suas funções nos moldes da ciência, da técnica e, consequentemente, do progresso. Por outro, essa espécie de "prelúdio republicano", como chamou Sevcenko (1998), também precisava chegar ao campo. Nesta perspectiva, o sertanejo deveria ser preparado para atuar no ambiente rural e, aos poucos, ser inserido no ideal de progresso, uma vez que, para republicanos como Monteiro Lobato, a prosperidade da nação era ameaçada por fortes contrastes entre o 
campo e a cidade, além disso, problemas ligados à saúde pública passavam a ser preocupação não apenas de médicos, mas de intelectuais e políticos da época. A ideia de modernidade e desenvolvimento da nação republicana vinha atrelada ao princípio de racionalização também dos corpos. Como afirma Rossi (2003, p.230) “A racionalização se estendia, também, pela finalidade de se criar um corpo que fosse sinônimo de aplicação dos conhecimentos científicos, corpos que simbolizassem a modernidade". Neste contexto, o Almanaque, representado pelos seus produtores como propagador dos modernos conhecimentos científicos, contribuiu para o seu sucesso e, também, dos produtos farmacêuticos Fontoura, por ele divulgado. De acordo com o slogan, eram "medicamentos milagrosos para verminose e anemia, um fortificante da época, cujo produto é reconhecido até aos nossos dias com o nome de Biotônico Fontoura" (CARDOSO, 2006, p. 46). Em suas páginas, foram divulgadas evidências positivas em relação à fórmula de Fontoura, como, por exemplo:

E o grande remédio que combate o amarelão, esse mal terrível que tantos braços preciosos rouba ao trabalho, é a ANKILOSTOMINA. Assim como o grande conservador da saúde, que produz energia, força e vigor, chama-se BIOTÔNICO FONTOURA (LOBATO, 1950, p. 12).

Persuasivo em suas colocações acerca da importância e eficácia do tônico formulado por Fontoura, importa considerar que ele foi pioneiro no que podemos chamar de primeira propaganda de massa nacional. O discurso textual desse livreto atendeu a uma série de requisitos que, combinados, asseguraram o sucesso do Almanaque. Ao se referir às tiragens de suas primeiras edições, observa Chartier (1999, p. 139) que "sua importância para a cultura brasileira se mede em suas enormes tiragens de dois ou três milhões de exemplares e sua forte presença nas lembranças de leitura, ou de escuta, dos mais modestos leitores". Este número de tiragem alcançou, na última edição do Almanaque, em 1982, o número recorde de 100 milhões de exemplares.

É possível afirmar que a propagação do Almanaque desempenhou um papel preponderante que envolveu estratégias e práticas de leituras. O Almanaque, distribuído, a princípio, apenas em farmácias, também adentrou os muros das escolas, transformando-se em material de leitura obrigatória de muitos jovens e crianças. Depoimentos de sujeitos que, em suas infâncias, em suas épocas de escola, utilizaram o Almanaque Biotônico Fontoura como material de leitura permitem esse argumento. Vejamos o depoimento de um imigrante japonês, referindo-se aos seus primeiros anos de experiência escolar no Brasil, no qual ele menciona a prática de leitura apoiada no Almanaque Biotônico Fontoura.

O material da escola era caderno brochura, de caligrafia, em que eu copiava várias vezes a mesma letra e o livro "Caminho Suave" - a cartilha - que agente usava até a $4^{\mathrm{a}}$ série. Pra entrar na sala de aula a gente cantava o Hino Nacional. Mas a escola era muito precária mesmo, não se oferecia material, não tinha nada de livro de leitura. O que eu lia 
era fora da escola e aquilo que eu ganhava. Eu me lembro que eu lia muito o "Jeca Tatu", um reclame que vinha num livrinho pequeno que entregavam na escola, do Biotônico Fontoura Aparecia o Jeca, lá, descalço. Daí entrava o bichinho no pé e ele ficava mal, com amarelão, barrigudo[...] Daí era só tomar o Biotônico Fontoura e virava empresário, fazendeiro[...] Até os porcos usavam sapatinho, sabe? (HANAYAMA, 2007, p. 11)

Mesmo tratando de um trecho curto e baseado na memória de um leitor, não se pode minimizar uma informação importante oferecida pelo depoente: "Eu me lembro que eu lia muito o 'Jeca Tatu' um reclame que vinha num livrinho pequeno que entregavam na escola, do Biotônico Fontoura". Outros depoimentos foram chegando ao alcance de nossas vistas. Vejamos:

Quando eu estava no segundo ano da Escola de Aparecido Bonito, que fica em Santa Fé do Sul, houve uma epidemia de amarelão. A prefeitura fez um programa de prevenção, principalmente nas escolas rurais. Como a maioria das crianças andava descalço, eram barrigudos, fracos e com vermes, uma senhora da cidade que era "metida" a médica, examinava os olhos, boca e ouvido das crianças, distribuindo um vidro de Biotônico para cada criança, por mês. Quando os médicos foram na escola chamaram os pais para dar uma palestra sobre a doença. Distribuíram o Biotônico e o livrinho. A partir daí, na minha casa, sempre se consultava este livrinho para tudo. O único irmão que lia, lia para nós todos (PARK, 1998, p. 103).

Pode-se observar que esse material, criado com um intuito publicitário e de educação dos hábitos, contou com diferentes estratégias de inserção no meio social. É possível afirmar que a circulação desse livreto, como muitos o chamavam, esteve presente na prática cotidiana escolar. O Almanaque adentrou os muros da escola e também os lares, configurando-se em um "livro" de leitura, guardado e passado de geração a geração. Vejamos o que diz uma leitora:

Mas aí eu vou contar pra você a história do meu primeiro livro de leitura. Logo quando eu me alfabetizei, já em 1949, meu pai que tinha guardado um livrinho, que não é bem um livrinho, é um almanaque, almanaque do Biotônico Fontoura, o famoso almanaque [[...]] Porque depois que eu me deleitei, que eu li várias vezes, aí meu pai guardou e passou para a minha irmã quando foi alfabetizada, [[...]] Quando ela foi alfabetizada, ela leu também, e ele guardou de novo, aí quando chegou a vez do meu irmão, leu também, pai guardou, e a minha irmã caçula idem, e assim foi preservado o almanaque (GOULARD, 2009, p. 91).

Do reconhecimento da importância do Almanaque para o letramento pode-se destacar dois aspectos: o primeiro com relação à formação de leitores, o segundo diz 
respeito ao depoimento de uma professora que, depois de muito tempo, sublinha em suas memórias da infância seu entrelaçamento literário com o Almanaque Biotônico Fontoura.

Esse livro, o almanaque, é o tesouro que eu guardo com todo o carinho, com todo cuidado. Porque é a lembrança do meu pai, que foi a figura masculina[...] mais importante da minha vida[...] Ele era uma pessoa que tinha pouca instrução[...] Ele tinha pouca, assim[...]escolaridade, mas ele tinha a poesia no que ele falava. Ele era assim, sabe, uma criatura mágica (GOULARD, 2009, p. 92).

Vários são os caminhos que levaram à leitura do Almanaque na infância, e não menos variados são os tipos de cuidados que se tem para com eles. Essa leitora desloca-se de seu tempo presente para um tempo passado, numa relação direta com o conhecimento que mantém arraigado a respeito do Almanaque Biotônico Fontoura e da história do Jeca Tatuzinho. O contato com esse material em sua infância desenvolveu práticas de leitura e, também, gerou afetividade. O efeito dessa força instiga-a, até o momento de seu depoimento, a vivenciar a diversidade de saberes e afetos que aquele material lhe proporcionou.

Também é importante destacar a forma didática como o Almanaque foi construído. $\mathrm{O}$ fato de seus idealizadores terem associado imagens visuais ao texto escrito permitiu que pessoas analfabetas também tivessem acesso às informações descritas no almanaque. Isso garantia não apenas a constituição de significados, como também a assimilação de procedimentos higiênicos que eram defendidos por intelectuais e sanitaristas.

Sempre achei que minha mãe soubesse ler e escrever, pois a vi inúmeras vezes dar ao Almanaque Biotônico Fontoura um tratamento de pessoa letrada: folheava-o com cuidado, demorava um tempo diferente em cada página e tecia comentários diversos que a mim pareciam ser derivados daquilo que estava lendo, já que seu olhar ora era dirigido a mim, ora ao texto (SILVA, 1997, p. 12).

Práticas como as descritas deixam ver a diversidade e as potencialidades dos usos que se fez do Almanaque. Por outro lado, sua penetração e a conquista do gosto brasileiro podem ser entendidas como resultado de um triunfo publicitário, um importante instrumento de propagação de novos costumes e comportamentos nos sujeitos. Assim diz uma leitora:

Eram folhetos ilustrados com a imagem do Jeca Tatu cagando no matinho, a barriga inchada de vermes, o amarelão, a inércia. Na minha cabeça de menina, a idéia cresceu assim: nunca ser como o Jeca Tatu. Depois, já vivendo em São Paulo, a figura do Jeca confirmou-se na derivação cômica dela: Mazzaropi. Só muito mais tarde me surpreendi ao descobrir que o interior paulista, de onde vinham Jeca Tatu e 
Mazzaropi, era outra coisa. Mas essa passagem, a transformação do Jeca Tatu em novo rico, não ficaria bem elaborada na minha cabeça (PARK, 1998, p. 91).

É possível observar que o Almanaque Biotônico Fontoura foi utilizado como material de leitura por diferentes sujeitos. Práticas de leituras que proporcionaram uma experiência e, como tal, algo imprevisível, um caminho para o desconhecido, uma aventura que produziu subjetividade, e seus efeitos não puderam ser controlados ou previstos. Ao ler, cada indivíduo busca um significado para aquilo que lê, faz relações internas com seus conhecimentos, cria expectativas, busca finalidades. Mesmo feita de modo silencioso e solitário, a leitura não deixa de ser um processo dinâmico. Para Chartier (1988, p. 123), "a leitura é pratica criadora, atividade produtora de sentidos singulares, de significações de modo nenhum redutíveis às intenções dos autores de textos ou fazedores de livros"; isso acontece porque, a partir do momento que entendo o livro como um produto manufaturado, constato a não capacidade de controle do autor em relação à forma de leitura da sua obra. Como afirma Chartier (1994, p. 17), "os autores não escrevem livros: não, eles escrevem textos que se tornam objetos escritos, manuscritos, gravados, impressos e, hoje, informatizados." Ao que parece, é o leitor que presa à construção dos significados daquilo que lê chegando, às vezes, a desconstruir as ideias originais do autor.

Podemos dizer que as reações do leitor podem significar muitas coisas ao final da leitura, e seria arriscado ao autor ou emissário validar com certeza apenas uma. O que ele faz é, no mínimo, preliminar sobre o possível período histórico no qual o texto foi produzido e sugerir ao destinatário, aqui tratado como leitor, uma hipótese interpretativa daquilo que escreve. A ideia do autor registrada em forma de mensagem escrita, ou seja, de um texto, trata-se da sua interpretação particular a respeito do assunto que escreve. Compartilhamos com o ponto de vista de Chartier (1994, p. 35-36), ao afirmar que o autor é:

[[...]] ao mesmo tempo, dependente e reprimido. Dependente: ele não é o mestre do sentido, e suas intenções expressas na produção do texto não se impõem necessariamente nem para aqueles que fazem desse texto um livro (livreiros - editores ou operários da impressão), nem para aqueles que dele se apropriam para a leitura. Reprimido: ele se submete às múltiplas determinações que organizam o espaço social da produção literária, ou que, mais comumente, delimitam as categorias e as experiências que são as próprias matrizes da escrita.

Neste sentido, o texto é uma alegoria baseada numa suposta realidade que, ao ser postado, fica sujeito às várias hipóteses interpretativas e conflitantes. Isso atribui força à leitura, tornando-a capaz de por fim às abordagens que, particularmente, combatiam interpretações diferentes daquelas propostas pelo autor no momento da criação, ficando evidente uma tendência que busca não somente examinar o ato de ler, mas que considera 
a leitura como uma das dimensões constitutivas do texto. Tudo isso contribui para expandir tanto as formas de ler como as de estudar essas mesmas formas e integrá-las a outros campos das ciências humanas, como a Educação, Antropologia, História, entre outras, e não apenas à Linguística ou Literatura.

Construir uma unidade de pensamento a respeito de um texto é algo praticamente impossível. Afinal, o texto está diante do impulso cooperativo dos mais variáveis e incontáveis leitores que existem e suas interpretações muitas vezes divergem entre si e entre o próprio texto que teve de base. Mas, afinal, como podemos entender essas interpretações e usos feitos pelos leitores?

Assim como a história da leitura, poderíamos escrever também a história da interpretação. Uma não existiria sem a outra, mas a luz dessa relação não é objetiva e trava diferentes posições teóricas no campo de estudos da leitura. Contudo, vale considerar que, ao escrever a história do Jeca Tatuzinho e produzir o Almanaque Biotônico Fontoura, Lobato teve uma intenção prévia, pois tinha como objetivo alertar seus leitores para a aquisição de novas práticas higiênicas, para o interesse pelos estudos, a importância do trabalho para o progresso pessoal e da nação, os benefícios da ciência. Em suma, objetivava um sertanejo bem-sucedido nos aspectos culturais, sociais, educacionais e de hábitos saudáveis.

Mesmo à deriva infinita de sentidos, os textos possuem seus limites interpretativos. Um afastamento interpretativo exacerbado daquilo que se lê pode implicar em variáveis que desvinculam a própria construção de sentidos do texto de sua matriz primária, deixando de assumir a propriedade de interpretação e passando a caracterizar-se, em ultima instância, como um novo texto a respeito de um assunto derivado de seu original. Neste sentido, Umberto Eco (1995) comunga da ideia que há diferenças entre "usar" um texto e "interpretá-lo", pois, à medida que o uso amplia os sentidos de um texto, a interpretação, por outro lado, respeita a coerência deste.

Os usos feitos do Almanaque envolvem pensar nos desvios provocados por seus consumidores. No entanto, para os limites deste artigo, buscamos identificar o uso material do Almanaque Fontoura. Nestes termos, no espaço escolar, ele se configurou como um instrumento de leitura e aprendizagem não apenas do conteúdo de educação sanitária por ele veiculado, mas também pelo aprendizado da leitura e escrita. Transformado em livro de leitura, o almanaque figurou na cultura escolar, nas primeiras décadas do século XX, como material de apoio didático.

\section{Referências}

CARDOSO, N. A. A. As criações neológicas em Monteiro Lobato: para a construção de um glossário. Uberlândia: Universidade Federal de Uberlândia, Instituto de Letras e Linguística, 2006.

CHARTIER, R. A história cultural: entre práticas e representações. Rio de Janeiro: Ed. Bertrand Brasil, 1988. 
A ordem dos livros: leitores, autores e bibliotecas na Europa entre os séculos XIV e XVIII. Brasília, DF: Ed. UnB, 1994.

A aventura do livro: do leitor ao navegador. São Paulo: Editora da UNESP, 1999.

ECO, U. Os limites da interpretação. Tradução de Pérola de Carvalho. São Paulo: Perspectiva, 1995 (Coleção Estudos).

GOULARD, I. do C. V. O livro: objetivo de estudo e de memória. Campinas: Unicamp, 2009.

HANAYAMA, E. Acolhendo a alfabetização nos países de língua portuguesa. São Paulo, v. 2, n. 4, Marzo/Ago. 2007. Disponível em: <http://www.revistasusp. sibi.usp. br/scielo.php? script=sci_art text\&pid=S1980-76862007000200012\&lng=es\&nrm=iso $>$. Acesso em: 5 mar. 2010.

LOBATO, M. Almanaque do Biotônico (Fontoura). São Paulo: Instituto Medicamenta, 1950. Ilustrado. 32pp. Dimensões de 13,5 x 18,5 cm. Variedades. Propagandas de Medicamentos.

. Urupês. 27. ed. São Paulo: Brasiliense, 1982.

PARK, M. B. Histórias e leituras de almanaques no Brasil. Campinas: Mercado das Letras S/A FADESP, 1998.

. De Jeca Tatu a Zé Brasil: a possível cura da raça brasileira. Revista Sociedade e Agricultura, Rio de Janeiro: CPDA/UFRJ, v. 13, p. 143-150, out. 1999. Disponível em: <http://bibliotecavirtual.clacso.org.ar/ar/libros/brasil/cpda/ estudos/treze/park13.htm>. Acesso em: 22 ago. 2009.

ROSSI, E. R. "Insuladas tribos". A escola primária e a forma de socialização escolar: São Paulo (1912-1920). 2003. Tese (Doutorado em História) - Universidade Estadual Paulista Júlio de Mesquita Filho, Assis.

SEVCENKO, N. O prelúdio republicano, astúcias da ordem e ilusões do progresso In: . (Org.). História da vida privada no Brasil: República: da Belle Époque à era do rádio. São Paulo, Companhia das Letras, 1998. v. 3, p. 7-47.

SILVA, M. da. Metáforas e entrelinhas da profissão docente. São Paulo: Pioneira Thomson Learning, 1997. 


\section{Notas}

${ }^{1}$ Mestre em Educação pela Programa de Pós-Graduação em Educação da Universidade Estadual de Maringá.

${ }^{2}$ Professora Adjunta do Departamento de Fundamentos da Educação da Universidade Estadual de Maringá. e do Programa de Pós-Graduação em Educação da Universidade Estadual de Maringá.

${ }^{3}$ Professora Adjunta do departamento de Fundamentos da Educação e do Programa de Pós-Graduação em Educação da Universidade Estadual de Maringá.

\section{Recebido em agosto-2013}

Aprovado em setembro-2013 